\title{
Medidas econômicas voltadas para a redução dos impactos da Covid-19
}

\author{
Economic measures to reduce the impacts of Covid-19 \\ Medidas económicas para reducir los impactos del Covid-19
}

Recebido: 02/11/2021 | Revisado: 12/11/2021 | Aceito: 19/02/2022 | Publicado: 01/03/2022

\author{
Jorcelyo Alencar Lima \\ ORCID: https://orcid.org/0000-0002-5530-7937 \\ Universidade Federal do Tocantins, Brasil \\ E-mail: j.alencar2008@hotmail.com \\ Elisangela de Andrade Borges Alencar \\ ORCID: https://orcid.org/0000-0002-6836-1692 \\ Universidade Estadual do Maranhão, Brasil \\ E-mail: elaborges2000@gmail.com \\ Graicy Cavalcante Fonseca \\ ORCID: https://orcid.org/0000-0002-0038-2323 \\ Tribunal Regional do Tocantins, Brasil \\ E-mail: graicy@tre-to.jus.br
}

\begin{abstract}
Resumo
O início do ano de 2020 é marcado pela pandemia do coronavírus. Além dos efeitos sobre a saúde pública, a doença vem impactando também na economia mundial. O presente artigo tem como objetivo mostrar a pandemia da Covid19 na realidade brasileira em que a ideologia do lucro e da economia prevalece sobre os valores importantes da vida. No capitalismo a desigualdade social é gritante e preocupam o Conselho Nacional de Saúde (CNS) no enfrentamento da Covid-19 no Brasil. e sempre são os mais pobres que, além de perder direitos, pagam a conta. A pandemia da Covid-19, que provoca a mais grave crise sanitária no mundo neste primeiro quarto do século XXI, gerou muitos e diversos debates. De um especialista a uma dona de casa, o assunto é o mais comentado. E cada um, a sua escolha, faz a defesa que tem mais proximidade com seu histórico de vida e relações pessoais. É ainda fundamental ressaltar que nesse contexto em que são necessárias medidas drásticas para conter a circulação de pessoas, uma carga ainda maior de trabalho doméstico e de cuidado com as crianças, idosos e doentes recai sobre as mulheres, principalmente as mulheres negras. A pesquisa foi bibliográfica, descritiva e quantitativa sobre o tema em tela. Conclui-se que o cenário pode ser revertido, caso o governo se comprometa a entregar reformas econômicas e promova privatizações relevantes. Desta feita, só uma mudança profunda nas expectativas dos investidores sobre as potencialidades de negócios no Brasil e no mundo seria capaz de compensar os efeitos econômicos danosos do coronavírus.
\end{abstract}

Palavras-chave: Covid-19; Pandemia; Economia; Saúde; Capitalismo.

\begin{abstract}
The beginning of the year 2020 is marked by the coronavirus pandemic. In addition to the effects on public health, the disease has also impacted the world economy. This article aims to show the Covid-19 pandemic in the Brazilian reality in which the ideology of profit and economy prevails over the important values of life. In capitalism, social inequality is striking and concerns the National Health Council (CNS) when facing Covid-19 in Brazil. and it is always the poorest who, in addition to losing rights, pay the bill. The Covid-19 pandemic, which causes the most serious health crisis in the world in this first quarter of the 21st century, has generated many and diverse debates. From an expert to a housewife, the subject is the most talked about. And each one, at his choice, makes the defense that is closest to his life history and personal relationships. It is also essential to emphasize that in this context in which drastic measures are needed to contain the circulation of people, an even greater burden of domestic work and care for children, the elderly and the sick falls on women, especially black women. The research was bibliographic, descriptive and quantitative on the topic at hand. It is concluded that the scenario can be reversed, if the government commits to deliver economic reforms and promotes relevant privatizations. This time, only a profound change in investors' expectations about business potential in Brazil and in the world would be able to offset the harmful economic effects of the coronavirus.
\end{abstract}

Keywords: Covid-19; Pandemic; Economy; Health; Capitalism.

\section{Resumen}

El comienzo del año 2020 está marcado por la pandemia de coronavirus. Además de los efectos sobre la salud pública, la enfermedad también ha tenido un impacto en la economía mundial. Este artículo tiene como objetivo mostrar la pandemia de Covid-19 en la realidad brasileña en la que la ideología del lucro y la economía prevalece sobre los valores importantes de la vida. En el capitalismo, la desigualdad social es llamativa y preocupa al Consejo Nacional de Salud (CNS) ante el Covid-19 en Brasil. y siempre son los más pobres quienes, además de perder 
derechos, pagan la factura. La pandemia de Covid-19, que provoca la crisis sanitaria más grave del mundo en este primer cuarto del siglo XXI, ha generado muchos y diversos debates. De experta a ama de casa, el tema es el que más se habla. Y cada uno, a su elección, hace la defensa más cercana a su historia de vida y relaciones personales. También es fundamental destacar que en este contexto en el que son necesarias medidas drásticas para contener la circulación de personas, una carga aún mayor del trabajo doméstico y del cuidado de los niños, los ancianos y los enfermos recae sobre las mujeres, especialmente las negras. La investigación fue bibliográfica, descriptiva y cuantitativa sobre el tema en cuestión. Se concluye que el escenario se puede revertir, si el gobierno se compromete a realizar reformas económicas y promueve las privatizaciones pertinentes. Esta vez, solo un cambio profundo en las expectativas de los inversores sobre el potencial empresarial en Brasil y en el mundo podría compensar los efectos económicos dañinos del coronavirus.

Palabras clave: Covid-19; Pandemia; Economía; Salud; Capitalismo.

\section{Introdução}

No cenário atual, a pandemia da Covid-19 acarreta a mais grave crise sanitária mundial deste primeiro quarto do século XXI. Foco de diversos e relevantes debates, esse tema tem sido discutido por especialistas e leigos, onde cada indivíduoexpressa opiniões relacionadas a vivências próprias e relacionamentos interpessoais.

Aliado a isso, apresenta-se uma outra questão a ser discutida mais limitada, porém com um impacto semelhante, que diz respeito ao tipo de desenvolvimento econômico que o mundo deseja adotar. Trata-se de uma discussão essencial que tem como centro o ser humano e da qual a sociedade deve participar.

A pandemia provocada pelo coronavírus atingiu significativamente o capitalismo. A partir de então surgem necessidades relativas a melhorias, redução de gastos e atividades empreendedoras como opções para assegurar subsistência às famílias desamparadas e impossibilitadas de trabalhar em meio a conjuntura apresentada. Assim, temas anteriormente considerados "socialistas" passaram a ter relevância, tais como: possuir um sistema público de saúde, luta contra desigualdades sociais, renda básica e um Estado intervencionista.

Desde o princípio, a gestão do Ministério da Saúde do Brasil foi marcada por ações que se notabilizaram por atacar o serviço público, extinguindo o programa Mais Médicos e reduzindo o Programa Saúde da Família. Sendo ainda mais afetadas com a demissão do ministro que, quando confrontado com a situação emergencial da pandemia, buscou apoiar-se no SUS que tentava destruir e passou a defender timidamente o isolamento social, única alternativa reconhecida pela experiência internacional para reduzir a velocidade que a doença era propagada e diminuir a demanda pelos equipamentos hospitalares escassos.

Nesse sentido, faz-se necessário que o mundo contemporâneo compreenda as medidas adotadas pelo capitalismo mesmo antes do surgimento da Covid-19 nos âmbitos da saúde, política, trabalho, educação, avanços tecnológicos, indivíduos, dentre outros.

O propósito desse artigo foi abordar a pandemia da Covid-19 no contexto brasileiro, em relação ao sistema capitalista, em que a concepção do lucro e da economia são mais valorizados do que a vida humana. Considera-se o capitalismo como um sistema econômico marcado por disparidades sociais, no qual os pobres são aqueles que mais sofrem em tempos de crise.

\section{Metodologia}

De acordo com Gil (2008), a pesquisa bibliográfica tem a função de elaborar fundamentos que imprimam coerência, a partir da leitura de publicações tais como livros, revistas, jornais, periódicos, artigos, estatísticas e matérias veiculadas na Internet, de autores contemporâneos, e posterior organização dos textos em forma de resumos, citações e interpretações.

Para Gil (2008), a pesquisa bibliográfica tem como finalidade colocar o pesquisador em contato com aquilo que foi escrito sobre determinado assunto, uma vez que a bibliografia pertinente oferece meios de definição e resolução, não apenas de problemas já conhecidos, bem como da exploração de novas áreas. 
A metodologia empregada no presente estudo é de natureza quantitativa e qualitativa, o que segundo Dias e Silva (2010), ocorre a partir da constatação de que envolve o uso de dados obtidos em publicações correlatas para a compreensão e explicação dos fenômenos.

\section{Covid-19}

\subsection{Definição}

A Covid-19 é uma infecção causada pela Síndrome Respiratória Aguda Grave (SARS-CoV-2) (Grupo De Estudo Coronaviridae Do Comitê Internacional De Taxonomia De Vírus, 2020). A identificação do vírus ocorreu em decorrência de um surto de pneumonia de origem desconhecida em Wuhan, na China, em dezembro de 2019 (Ren et al., 2020). O quadro clínico assemelha-se a uma infecção respiratória e a gravidade dos sintomas varia de um resfriado comum leve a uma pneumonia viral grave, que pode resultar em uma síndrome de desconforto respiratório agudo potencialmente fatal.

O cenário pandêmico do novo coronavírus caracteriza-se por sucessivas quedas nas bolsas de valores pelo mundo, e deve provocar um tombo no crescimento econômico do planeta em 2020. No Brasil, os choques de oferta e demanda provocados pela disseminação da doença provavelmente irão frear a recuperação da economia - não atendendo a expectativa de que, após a pequena elevação do Produto Interno Bruto (PIB) do ano passado, as ações desenvolvidas economicamente demonstrariam maior vigor em 2020 (Fontes, 2020).

\subsection{Epidemiologia}

A Organização Mundial da Saúde (OMS) foi informada, em 31 de dezembro de 2019, sobre a ocorrência de 44 casos com pneumonia de etiologia microbiana desconhecida, na cidade de Wuhan, China. A maior parte dos pacientes do surto relatou uma ligação com um grande mercado de frutos do mar e animais vivos (Mercado Atacadista de Frutos do Mar de Huanan) (Bmj Best Practice, 2020). A OMS anunciou que um novo coronavírus foi detectado em amostras obtidas desses pacientes. Testes laboratoriais descartaram síndrome respiratória aguda grave por coronavírus (SARS-CoV), síndrome respiratória do Oriente Médio (MERS)-CoV, influenza, gripe aviária e outros patógenos respiratórios comuns (OMS, 2020). A partir de então, o surto escalou com rapidez, e a OMS declarou emergência na saúde pública de importância internacional em 30 de janeiro de 2020 e, posteriormente, declarou pandemia no dia 11 de março de 2020.

Perante uma pandemia dessa dimensão, que representa um risco iminente para a vida de uma parte considerável da população mundial, não se pode deixar de perceber as consequências danosas dessa situação, resultando em óbitos antes mesmo da contaminação proveniente do novo coronavírus (Alves, 2015). Sendo que, além deste vilão invisível, a sociedade precisa lidar com aqueles que são visíveis e representam um perigo à existência humana, de modo ainda mais arrebatador: tratam-se de fatores que agem para atender os interesses econômicos, desconsiderando a vida de terceiros; recusam ou inferiorizam a realidade, mesmo com a expressão de reações receosas no que se refere à contaminação.

A partir dessa perspectiva, pode-se constatar que as pessoas que mais sofrem os efeitos causados pela pandemia da Covid-19 são os menos favorecidos economicamente, que são alienados pelo sistema e apresentam pouco pensamento crítico, permanecendo na cadeia de exploração econômica.

\subsection{Etiologia}

A Síndrome Respiratória Aguda Grave por Coronavírus 2 (SARS-CoV-2) é definida como um betacoronavírus, que foi descoberto em amostras de lavagem broncoalveolar obtida nos núcleos de enfermos com pneumonia de causa desconhecida na cidade de Wuhan, província de Hubei, China, em dezembro de 2019 (Ren et al, 2020). Os coronavírus constituem uma 
grande família de vírus de RNA envelopados, inclusive alguns que causam doenças em humanos (por exemplo, resfriado comum, Síndrome Respiratória Aguda Grave [SARS], síndrome respiratória do Oriente Médio [MERS] e outros que circulam entre mamíferos e aves.

\subsection{Fisiopatologia}

Relatórios preliminares sugeriram que o número reprodutivo $\left(\mathrm{R}_{0}\right)$, a quantidade de pessoas que adquirem a infecção de uma pessoa infectada, foi estimado entre 2.2 e 3.3 (Li; Guan; Wu, 2020). Entretanto, o $\mathrm{R}_{0}$ pode realmente ser menor à luz das medidas de distanciamento social que têm sido instituídas.

Avalia-se que as taxas de ataque secundária da SARS-CoV-2 sejam de $0.45 \%$ para contatos próximos de pacientes nos EUA.

Embora a fisiopatologia seja atualmente desconhecida, confirmou-se que o vírus se liga ao receptor da enzima conversora de angiotensina-2 (ECA2) em seres humanos, sugerindo uma patogênese semelhante à SARS (Lu; Zhao; Li, 2020. No entanto, uma característica estrutural única do domínio de ligação ao receptor da glicoproteína "spike" do SARS-Cov-2 (responsável pela penetração do vírus nas células hospedeiras) confere uma afinidade de ligação potencialmente maior para ECA2 nas células hospedeiras, comparado ao SARS-CoV (Chen; Guo; Pan, 2020). Um sítio de clivagem semelhante ao furin foi identificado na proteína de pico do vírus; isso não existe em outros coronavírus similares à SARS.

Com base em um diagnóstico de conjuntos de dados de sequenciamento do RNA de células únicas derivados dos principais sistemas fisiológicos humanos, os órgãos considerados mais vulneráveis à infecção por SARS-CoV-2 devido aos seus níveis de expressão de ACE2 incluem os pulmões, o coração, o esôfago, os rins, a bexiga e o íleo (Zou et al., 2020).

Evidências mecânicas de outros coronavírus sugerem que o SARS-CoV-2 pode diminuir a ECA2, resultando em um acúmulo excessivo tóxico da angiotensina-II, que pode induzir síndrome do desconforto respiratório agudo e miocardite fulminante (Hanff et al., 2020).

Atualmente, quando os governos impõem restrições a viagens e comércio, assim como bloqueiam cidades inteiras para impedir que a Covid-19 seja propagada, evidencia-se o quão frágil é o sistema alimentar globalizado. Mais restrições comerciais e de viagens podem limitar a fluência de alimentos importados, de países diversos ou regiões de um país em particular, com consequências devastadoras no ingresso de alimentos, principalmente, para os setores mais pobres. Isso é crítico para os países que importam mais de 50\% dos alimentos consumidos por suas populações. A acessibilidade aos alimentos também é considerada crítica para cidades com população superior a 5 milhões de pessoas que, para alimentar seus cidadãos, precisam importar não menos que 2.000 toneladas de mantimentos por dia, percorrendo uma média de 1.000 quilômetros. Claramente, este é um mecanismo alimentar altamente insustentável, facilmente perturbado por choques externos, como desastres naturais ou uma pandemia (Altieri et al., 2020).

\section{O Capitalismo e a Covid-19}

O capitalismo é considerado um sistema de opressão. A partir dessa declaração pode-se observar que há uma energia que impulsiona os indivíduos a sentimentos relacionados a insegurança, ausência de perspectiva e desordem. Em outros termos, conduzem os esforços a algo anterior a morte física, demandando o suor dos explorados para a obtenção de lucros exorbitantes e enriquecimento dos detentores de capital. Esse tipo de sistema é caracterizado por influenciar e determinar o modo de vida das pessoas por meio de fatores como o mercado e a especulação financeira, que induzem a tirarem proveito de tudo em um curto período de tempo (Castro et al., 2020). 
Historicamente, o capitalismo tem sua origem no princípio da Idade Moderna com o processo de industrialização e ascensão da burguesia, segundo a qual o lucro é superior aos valores humanos referentes a direitos como a igualdade social e preservação da natureza. De acordo com Marx e Engels, é inerente ao ser humano ações que expressem o seu modo de viver, dependendo de suas condições materiais.

Marcondes (2000) defende a concepção de que a forma como os sujeitos vivem corresponde a sua forma de ser. Logo, o que eles são combina com o que é produzido e a maneira como produzem, sendo que a conduta dos indivíduos é influenciada pelas condições materiais oferecidas no decorrer da produção.

Partindo dessa premissa, constata-se que o ser humano é concebido como produtor e produto, mas para Marx o interesse principal diz respeito ao distanciamento entre as condições naturais de produção da vivência do homem e as suas atividades associadas ao labor e capital (Barbosa, 2002). Diante disso, o modo de produção capitalista é caracterizado por estar sujeito ao trabalho, à propriedade e ao lucro. Além disso, também encontra-se alienado a preceitos ideológicos e inverte por completo o trabalho humano.

Os dados do Oxfam apontam que a concentração de renda sofreu um aumento expressivo no início de 2020, de modo que 2.153 bilionários do mundo são detentores de uma riqueza que ultrapassa $60 \%$ da população mundial, isto é, 4,6 bilhões de indivíduos. Tal discrepância também pode ser percebida no Brasil, ao observa-se os dados publicados pela revista Forbes em 2019, que listam os 10 maiores bilionários brasileiros. Em contrapartida, o jornal El País mostra um país constituído por 13,5 milhões de miseráveis.

O Índice de Desenvolvimento Humano (IDH) apresentado pela ONU demonstra como encontra-se a qualidade de vida dos menos favorecidos. No relatório produzido, o Brasil tem a sua realidade exposta: ausência de uma educação de qualidade acessível, um sistema de saúde desgastado, carência de saneamento básico e de transportes públicos eficientes, ausência de salários justos e de uma política fiscal adequada.

O diagnóstico é da Instituição Fiscal Independente (IFI), no Relatório de Acompanhamento Fiscal (RAF) $\mathrm{n}^{\mathrm{o}} 38$, divulgado nesta semana. No documento, a IFI aponta que, dependendo da extensão dos choques e das medidas de política econômica adotadas pelos países, pode haver aumento do desemprego (Fontes, 2020).

A partir de uma análise geral, as providências adotadas pretendem minimizar os impactos causados à movimentação de caixa das empresas, prover renda para as famílias desfavorecidas e expandir a capacidade dos serviços de saúde. Contudo, nem todas as medidas tiveram as suas implicações financeiras expostas. Os Estados Unidos, por exemplo, apresentam valores que já alcançam a 6,3\% do PIB, porém o país está ajustando com o Congresso o aumento para 11,3\% do PIB (Pires, 2020).

Enquanto no Reino Unido, foi divulgado que as medidas utilizadas corresponderam a 17\% do PIB. Sendo que a ação mais expressiva foi representada pelo oferecimento de garantias públicas de até £330 bilhões, tendo em vista que estas minimizam os riscos dos empréstimos bancários, pois caso o inadimplente não quite as suas dívidas, o governo realiza o pagamento. Uma das medidas anunciadas foi a reposição de até $80 \%$ da renda de funcionários em lay off, correspondendo a um valor mensal de $£ 2.500$. Tem-se, portanto, o mais forte programa voltado à transferência de renda, o qual não teve o resultado financeiro publicado (Pires, 2020).

Por sua vez, a Espanha, divulgou um programa que, até agora, alcança 17\% do PIB. De modo que, além dos cauções públicos para empréstimos e a transferência de renda aos trabalhadores informais, também foram implementadas ações responsáveis por assegurar a prestação de serviços públicos básicos como eletricidade, água e internet, assim como a manutenção de renda com a interrupção de hipotecas imobiliárias. Em relação aos países da Alemanha e França, os valores correspondem a $12 \%$ e $13,1 \%$ do PIB (Pires, 2020). 
O governo do Brasil adotou um conjunto de medidas, como: a fusão do PIS com o FGTS e foram disponibilizados R\$ 5 bilhões para as MPEs utilizarem como capital de giro. Sendo assim, conforme apresentado no quadro 1 , dos 55 bilhões previstos, considera-se que somente R 30 bilhões são novos (Pires, 2020).

Quadro 1 - Quadro resumo.

\begin{tabular}{|l|r|}
\hline MEDIDAS & R\$ bi \\
\hline PIS/PASEP & 20 \\
\hline Stanstill de operações diretas & 19 \\
\hline Stanstill de operações indiretas & 11 \\
\hline Capital de giro para MPE & 5 \\
\hline TOTAL & $\mathbf{5 5}$ \\
\hline
\end{tabular}

Fonte: Pires (2020).

Entretanto, as outras linhas compreendem novas negociações de operações de crédito em um contexto não muito benéfico. Em relação às operações indiretas, o risco envolvido é atribuído ao banco operador do financiamento e a alíquota a ser arrecadada é constituída por TLP + comissão do BNDES + spread do banco operador. Esse valor deve permanecer maior que $6,3 \%$ em termos reais, aproximando-se de $9 \%$ em termos nominais. Sendo que a taxa Selic cairá nos meses seguintes, esses valores apresentados são considerados pouco competitivos para a maior parte das operações.

O quadro 2 apresenta as medidas fiscais adotadas pelo governo. Por meio do qual, observa-se que o total corresponde a um valor expressivo de R 844 bilhões (11,6\% do PIB). Todavia, a ação que representou maior impacto diz respeito à diminuição do requerimento de capital dos bancos que autorizaram $\mathrm{R} \$ 672$ bilhões, a fim de estender a capacidade de crédito. Devido ao fato de não possuir caráter fiscal e o governo só necessitar dela quando os bancos públicos forem mais ativos, é fundamental mensurar as medidas em sua abrangência total, eliminando a ação mencionada. Desse modo, pode-se notar que, além de escasso, o valor divulgado corresponde apenas a $2,86 \%$ do PIB.

Quadro 2 - Quadro resumo.

\begin{tabular}{|c|c|c|}
\hline & Em R\$ bi & $\%$ do PIB \\
\hline Antecipação de despesa (do $2^{\circ}$ semestre para $01^{\circ}$ semestre) & $\mathbf{5 8 , 8}$ & $\mathbf{0 , 8 1 \%}$ \\
\hline $1^{\mathrm{a}}$ e $2^{\mathrm{a}}$ parcela do $13^{\mathrm{o}}$ em maio & 46,0 & $0,63 \%$ \\
\hline Abono salarial em junho & 12,8 & $0,18 \%$ \\
\hline Adiantamento de receita (do $1^{\circ}$ semestre para o $2^{\circ}$ semestre) & 52,2 & $0,72 \%$ \\
\hline FGTS diferimento de 3 meses & 30,0 & $0,41 \%$ \\
\hline Supersimples, parcela da União, diferimento de 3 meses & 22,0 & $0,31 \%$ \\
\hline Desoneração & 2,2 & $\mathbf{0 , 0 3 \%}$ \\
\hline Redução da contribuição ao sistema $\mathrm{S}$, em $50 \%$, por 3 meses & 2,0 & $\mathbf{0 , 0 3 \%}$ \\
\hline
\end{tabular}




\begin{tabular}{|c|c|c|}
\hline Desoneração de IPI sobre produtos necessários ao combate do Covid-19 & ND & \\
\hline $\begin{array}{l}\text { Zeragem do imposto de importação sobre produtos de uso médico hospitalar até o } \\
\text { final do ano }\end{array}$ & ND & \\
\hline Remanejamento de recursos & 39,1 & $0,54 \%$ \\
\hline Novos saques do FGTS, com base em recursos não sacados do PIS/PASEP & 21,5 & $\mathbf{0 , 3 0 \%}$ \\
\hline Mais recursos para o Bolsa Família & 3,1 & $0,04 \%$ \\
\hline Mais recursos para o SUS, com $\$$ do DPVAT & 4,5 & $0,06 \%$ \\
\hline Complementação de redução da jornada com o seguro desemprego & 10,0 & $0,14 \%$ \\
\hline Novas despesas & 20,0 & $\mathbf{0 , 2 8 \%}$ \\
\hline Coronavoucher & 15,0 & $0,21 \%$ \\
\hline Crédito extraordinário saúde & 5,0 & $0,07 \%$ \\
\hline Mais crédito & 672,0 & $9,26 \%$ \\
\hline Mais capital de giro para MPES no BNDES (PROGER) & 5,0 & $0,07 \%$ \\
\hline $\begin{array}{l}\text { Dispensa de provisão adicional para renegociação de créditos nos próximos } 6 \\
\text { meses }\end{array}$ & NA & \\
\hline $\begin{array}{l}\text { Redução temporária do requerimento de capital para ampliar capacidade de } \\
\text { concessão de crédito }\end{array}$ & 637,0 & $8,78 \%$ \\
\hline Standstill BNDES & 30,0 & $0,41 \%$ \\
\hline TOTAL & 844,3 & $11,63 \%$ \\
\hline TOTAL sem redução do requerimento de capital & 207,3 & $2,86 \%$ \\
\hline TOTAL sem redução do requerimento de capital e antecipação & 148,5 & $2,05 \%$ \\
\hline
\end{tabular}

Fonte: Pires (2020).

Aliado a isso, considera-se que diversas providências adotadas estão relacionadas a antecipações de despesa que terão baixo impacto, visto que a crise terá uma duração considerável, o total divulgado correspondeu a apenas 2,05\% do PIB. Ao comparar-se esse valor ao de outros países, que já representam quase $20 \%$, o conjunto de medidas implementadas não são satisfatórias (Pires, 2020).

Isso seria muito preocupante, dada a existência de um contingente de desocupados relativamente elevado, em torno de 12 milhões de pessoas, sem levar em consideração a parcela da população que está subempregada e os desalentados (Fontes, 2020).

A fuga de investimentos do Brasil e a crescente valorização do dólar já são sinais de que o mercado tem a mesma avaliação da IFI. No RAF divulgado em meio ao pânico causado pelo novo coronavírus, a Instituição aponta os principais vetores que fazem a crise da Covid-19 minar a recuperação da economia brasileira em 2020 (Fontes, 2020).

Em relação ao resultado do PIB do quarto trimestre de 2019, o PIB cresceu 1,1\%, após dois incrementos de $1,3 \%$ registrados em 2017 e 2018. Sob a ótica da oferta, o resultado de 2019 foi praticamente todo explicado pelo desempenho do 
PIB de Serviços. A indústria teve mais um desempenho frustrante no ano passado. Pela ótica da demanda, impulsionaram o resultado do PIB no período o consumo das famílias e a formação bruta de capital fixo, nesta ordem de importância.

A contribuição do setor externo para o PIB em 2019 foi negativa. No quarto trimestre de 2019, a expansão da economia foi de $0,5 \%$ frente ao trimestre anterior. No quarto trimestre, o PIB registrou aumento de $0,5 \%$ na comparação trimestral dos dados com ajuste sazonal, após incrementos de 0,6\% e 0,5\% nos trimestres imediatamente anteriores. Na comparação anual, houve acréscimo de $1,7 \%$ sobre o quarto trimestre de 2018. No segundo semestre de 2019, houve estímulo dos saques das contas do FGTS e do PIS/PASEP sobre o PIB, por meio de incentivo ao consumo das famílias (Tabela 1).

Tabela 1 - Taxas de variação do PIB.

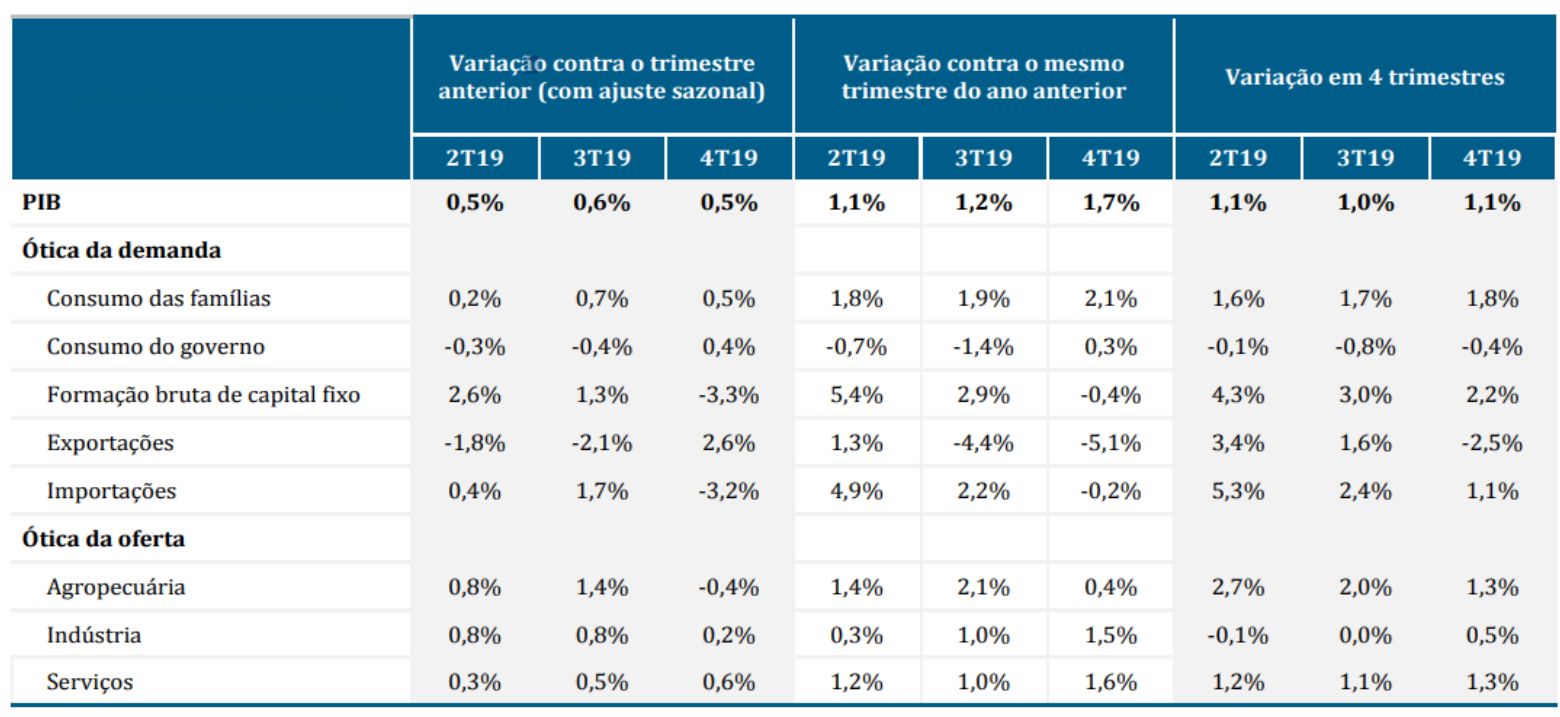

Fonte: IBGE. Elaboração IFI (2020).

Absorção doméstica explica a desaceleração observada no PIB em 2019 frente a 2018. A Tabela 2 apresenta as contribuições, em pontos percentuais, para a taxa acumulada do PIB em quatro trimestres em 2018 e 2019 , a partir do comportamento da absorção doméstica e das exportações líquidas. Fundamentalmente, o menor crescimento da economia verificado em 2019 ocorreu em razão da desaceleração da absorção doméstica, cujo impacto diminuiu de 2,7 pontos percentuais no quarto trimestre de 2018 para 1,3 ponto percentual no último trimestre de 2019. No mesmo período, as exportações líquidas saíram de $-1,3$ ponto percentual para $-0,2$ ponto percentual.

Tabela 2 - Contribuições (em P.P.) para a taxa acumulada em quatro trimestres do PIB (P.P.)

\begin{tabular}{|c|c|c|c|c|c|c|c|c|}
\hline & 2018.1 & 2018.II & 2018.|II & 2018.IV & 2019.1 & 2019.1I & 2019.|II & 2019.IV \\
\hline Absorção interna & 2,3 & 2,7 & 3,0 & 2,7 & 2,1 & 2,1 & 1,5 & 1,3 \\
\hline Consumo das famílias & 1,9 & 1,9 & 1,7 & 1,3 & 1,0 & 1,0 & 1,1 & 1,2 \\
\hline Consumo do governo & 0,0 & 0,0 & 0,1 & 0,1 & 0,0 & 0,0 & $-0,2$ & $-0,1$ \\
\hline Formação Bruta de Capital Fixo & $-0,1$ & 0,3 & 0,6 & 0,6 & 0,6 & 0,7 & 0,5 & 0,4 \\
\hline Variação de estoques* & $-0,6$ & $-0,4$ & $-0,5$ & $-0,7$ & $-0,5$ & $-0,4$ & $-0,1$ & 0,2 \\
\hline Exportações líquidas & $-0,8$ & $-1,0$ & $-1,4$ & $-1,3$ & $-1,0$ & $-1,0$ & $-0,5$ & $-0,2$ \\
\hline
\end{tabular}

* A variação de estoques (ou o investimento em estoques) corresponde à variação líquida nos estoques de bens finais e matérias-primas utilizadas no processo de produção. A rubrica é usada como elemento de equilíbrio de oferta e demanda de bens e serviços. Fonte: IBGE. Elaboração IF (2020). 
Os números da Tabela 2 sugerem que o consumo das famílias desacelerou mesmo na presença de estímulos (saque de recursos nas contas do FGTS e do PIS/PASEP). Não fosse essa medida, o crescimento da variável poderia ter sido menor no último ano.

Nessa base de comparação, no âmbito das despesas obrigatórias do governo central, merecem destaque: (i) o pagamento de benefícios previdenciários (RGPS), que subiu 0,8\%, em termos reais; (ii) as despesas de pessoal (inclui servidores ativos e inativos), que caíram 1,6\%; (iii) a compensação ao RGPS pela desoneração da folha, que teve redução de 40,5\%; e (iv) os gastos com subsídios, subvenções e Proagro, que sofreram redução de 40,2\% entre o ano passado e este ano (Tabela 3).

Tabela 3 - Despesas selecionadas do governo central - 2018 a 2020 - janeiro (R\$ bilhões correntes, VAR. \% REAL e \% do PIB)

\begin{tabular}{|c|c|c|c|c|c|c|c|c|c|}
\hline & \multicolumn{3}{|c|}{ jan/18 } & \multicolumn{3}{|c|}{ jan/19 } & \multicolumn{3}{|c|}{ jan/20 } \\
\hline & $\begin{array}{c}\mathbf{R} \$ \mathbf{b i} \\
\text { correntes }\end{array}$ & $\begin{array}{c}\text { Var.\% } \\
\text { real }\end{array}$ & $\%$ PIB & $\begin{array}{l}\text { R\$ bi } \\
\text { correntes }\end{array}$ & $\begin{array}{c}\text { Var.\% } \\
\text { real }\end{array}$ & $\%$ PIB & $\begin{array}{c}\text { R\$ bi } \\
\text { correntes }\end{array}$ & $\begin{array}{l}\text { Var.\% } \\
\text { real }\end{array}$ & $\%$ PIB \\
\hline Despesa total & 105,4 & $1,6 \%$ & $18,8 \%$ & 106,81 & $-2,3 \%$ & $18,5 \%$ & 107,57 & $-3,3 \%$ & $17,4 \%$ \\
\hline Benefícios previdenciários (RGPS) & 43,4 & $4,7 \%$ & $7,7 \%$ & 46,1 & $2,5 \%$ & $8,0 \%$ & 48,4 & $0,8 \%$ & $7,8 \%$ \\
\hline Pessoal (ativos e inativos) & 25,6 & $2,8 \%$ & $4,6 \%$ & 26,1 & $-1,8 \%$ & $4,5 \%$ & 26,8 & $-1,6 \%$ & $4,3 \%$ \\
\hline Abono e seguro desemprego & 5,5 & $-5,8 \%$ & $1,0 \%$ & 5,8 & $2,0 \%$ & $1,0 \%$ & 5,8 & $-5,0 \%$ & $0,9 \%$ \\
\hline Benefícios de Prestação Continuada (BPC) & 4,5 & $2,6 \%$ & $0,8 \%$ & 4,8 & $2,4 \%$ & $0,8 \%$ & 5,0 & $0,6 \%$ & $0,8 \%$ \\
\hline Compensação ao RGPS pelas Desonerações da Folha & 0,9 & $-19,1 \%$ & $0,2 \%$ & 1,0 & $9,0 \%$ & $0,2 \%$ & 0,6 & $-40,5 \%$ & $0,1 \%$ \\
\hline Fundeb & 2,9 & $8,4 \%$ & $0,5 \%$ & 3,1 & $3,8 \%$ & $0,5 \%$ & 3,4 & $3,6 \%$ & $0,5 \%$ \\
\hline Sentenças judiciais e precatórios (custeio e capital) & 0,1 & $-19,5 \%$ & $0,0 \%$ & 0,1 & $44,7 \%$ & $0,0 \%$ & 0,2 & $28,8 \%$ & $0,0 \%$ \\
\hline Subsídios, subvenções e Proagro & 6,0 & $-34,6 \%$ & $1,1 \%$ & 4,7 & $-25,5 \%$ & $0,8 \%$ & 2,9 & $-40,2 \%$ & $0,5 \%$ \\
\hline Obrigatórias & 100,8 & $1,3 \%$ & $18,0 \%$ & 102,6 & $-1,9 \%$ & $17,7 \%$ & 102,5 & $-4,1 \%$ & $16,6 \%$ \\
\hline Obrigatórias com controle de fluxo & 9,9 & $28,1 \%$ & $1,8 \%$ & 8,8 & $-14,8 \%$ & $1,5 \%$ & 8,3 & $-8,7 \%$ & $1,3 \%$ \\
\hline Discricionárias & 4,6 & $10,2 \%$ & $0,8 \%$ & 4,2 & $-12,1 \%$ & $0,7 \%$ & 5,1 & $16,2 \%$ & $0,8 \%$ \\
\hline PIB (R\$ bi correntes) & & & 559,8 & & & 578,7 & & & 619,2 \\
\hline
\end{tabular}

Fonte: IBGE. Elaboração IF (2020).

Outro ponto que chamou a atenção no RTN de janeiro foi o incremento verificado nas despesas discricionárias, que atingiram R\$ 5,1 bilhões, com aumento de 16,2\%, em termos reais, ante 2019. Dentro desse grupo, algumas despesas registraram incremento expressivo, parcialmente compensadas por fortes reduções praticadas em outros grupos de despesas.

Os grupos de despesas discricionárias que tiveram expansão digna de registro em janeiro foram: (i) saúde, que passou de R \$ 880,9 milhões em 2019 para R \$ 1.181,0 milhões em 2020 (aumento real de 28,7\%); (ii) transporte (alta de 21,7\%, a R\$ 451,1 milhões); (iii) segurança pública (+20,8\%, de R \$ 165,2 milhões a R \$ R \$ 207,8 milhões); e (iv) demais (crescimento de $56,9 \%$, a R \$ 1.529,3 milhões). A execução de restos a pagar pode explicar parte deste movimento, como tem salientado a STN.

Por outro lado, ainda no grupo de despesas discricionárias, sofreram fortes reduções as seguintes rubricas: (i) assistência social (-38,3\% real, de R\$ 140,5 milhões em janeiro de 2019 para R\$ 90,3 milhões em janeiro de 2020); (ii) administração (-42,6\%); e (iii) ciência e tecnologia (-42,6\%, alcançando o nível de R \$131,3 milhões).

Finalmente, cabe salientar que o quadro econômico de 2020 torna-se cada vez mais excepcional, na presença da crise do coronavírus. Este contexto específico requer medidas emergenciais e urgentes, que cabem perfeitamente no arcabouço fiscal vigente, sem necessidade de alteração do teto de gastos públicos, uma medida estrutural. A alteração da meta de resultado primário, por essa razão, não é motivo para piora de expectativas ou deterioração do quadro prospectivo. Se bem utilizada, a 
eventual redução da meta de primário seria suficiente para abarcar volume expressivo de créditos extraordinários para a Saúde e outras áreas, em uma ação pontual e eficiente de combate à crise do coronavírus.

A PEC Emergencial estabelece uma série de medidas de controle do crescimento das despesas. Algumas das mais importantes, do ponto de vista fiscal, estão relacionadas ao descumprimento da regra de ouro (art. 167, III). Enquanto a regra estiver sendo descumprida, a União fica proibida, entre outras coisas, de conceder reajustes, realizar concurso público, contratar servidores, criar despesas obrigatórias ou conceder benefícios tributários, ressalvadas exceções previstas na proposta. Boa parte das medidas são exatamente aquelas previstas para o descumprimento do teto de gastos.

A PEC emergencial permitiria acioná-las antes do rompimento do teto, dado que a regra de ouro já está sendo descumprida pela União em 2020. A violação à regra de ouro impede ainda a progressão na carreira de servidores e permite a redução em até $25 \%$ da jornada de trabalho com diminuição proporcional do salário.

Ainda mais importante é a possibilidade de a lei orçamentária conter previsões de despesas para exercícios seguintes, com a especificação dos investimentos plurianuais e daqueles em andamento. O processo orçamentário brasileiro é notoriamente míope em relação aos impactos fiscais no futuro de decisões tomadas no presente. Esse é um tema que, embora fuja do debate mais imediato sobre orçamento impositivo, deve ser levado adiante pelos órgãos centrais de planejamento e orçamento.

Tabela 4 - Projeções da IFI.

\begin{tabular}{|c|c|c|c|c|c|c|c|c|c|}
\hline & \multirow[b]{2}{*}{2014} & \multirow[b]{2}{*}{2015} & \multirow[b]{2}{*}{2016} & \multirow[b]{2}{*}{2017} & \multirow[b]{2}{*}{2018} & \multirow[b]{2}{*}{2019} & \multicolumn{3}{|c|}{ Projeções } \\
\hline & & & & & & & 2020 & 2021 & 2022 \\
\hline PIB - crescimento real (\% a.a.) & 0,50 & $-3,5$ & $-3,3$ & 1,3 & 1,3 & 1,1 & 2,2 & 2,5 & 2,5 \\
\hline PIB - nominal (R\$̦ bilhões) & 5.779 & 5.996 & 6.269 & 6.583 & 6.889 & 7.257 & 7.614 & 8.124 & 8.659 \\
\hline IPCA - acum. (\% no ano) & 6,41 & 10,67 & 6,29 & 2,95 & 3,75 & 4,31 & 3,52 & 3,56 & 3,45 \\
\hline Taxa de câmbio - fim de período (R\$/US\$) & 2,66 & 3,90 & 3,26 & 3,31 & 3,87 & 4,03 & 4,03 & 3,87 & 3,86 \\
\hline Ocupação - crescimento (\%) & 1,5 & 0,0 & $-1,9$ & 0,4 & 1,4 & 2,0 & 1,3 & 1,4 & 1,4 \\
\hline Massa salarial - crescimento (\%) & 4,0 & $-1,1$ & $-3,2$ & 1,9 & 3,0 & 2,5 & 2,6 & 2,6 & 2,7 \\
\hline Selic - fim de período (\% a.a.) & 11,75 & 14,25 & 13,75 & 7,00 & 6,40 & 4,50 & 4,50 & 6,00 & 6,50 \\
\hline Juros reais ex-post (\% a.a.) & 5,02 & 3,23 & 7,02 & 3,94 & 2,56 & 0,19 & 0,95 & 2,35 & 2,95 \\
\hline Resultado Primário do Setor Público Consolidado (\% do PIB) & $-0,56$ & $-1,86$ & $-2,48$ & $-1,68$ & $-1,57$ & $-0,85$ & $-1,56$ & $-0,98$ & $-0,68$ \\
\hline d/q Governo Central & $-0,35$ & $-1,95$ & $-2,54$ & $-1,80$ & $-1,69$ & $-1,22$ & $-1,63$ & $-1,11$ & $-0,63$ \\
\hline Juros Nominais Líquidos (\% do PIB) & $-5,39$ & $-8,37$ & $-6,49$ & $-6,09$ & $-5,50$ & $-5,06$ & $-3,86$ & $-4,15$ & $-4,69$ \\
\hline Resultado Nominal (\% do PIB) & $-5,95$ & $-10,22$ & $-8,98$ & $-7,77$ & $-7,08$ & $-5,91$ & $-5,42$ & $-5,13$ & $-5,37$ \\
\hline Dívida Bruta do Governo Geral (\% do PIB) & 56,28 & 65,50 & 69,84 & 73,74 & 76,53 & 75,77 & 79,33 & 79,51 & 80,03 \\
\hline
\end{tabular}

Fonte: IBGE. Elaboração IF (2020).

A aprovação de um auxílio emergencial no valor correspondente a $\mathrm{R} \$ 600,00$ aos trabalhadores que possuíam baixa renda e foram afetados pela pandemia (Lei 13.892, de 2020) foi considerada uma conquista para o país. Entretanto, o valor garantido pelo auxílio é muito baixo perante as demandas sociais dos indivíduos que se encontram em risco social na atual conjuntura caracterizada pela necessidade de distanciamento social. Além disso, uma parte considerável da população não consegue realizar o cadastro, como por exemplo os moradores de ruas.

De tal modo, faz-se necessário que os Estados e Municípios prestem assistência e realizem a complementação financeira às famílias carentes que vivem na informalidade ou que tiveram os seus empregos afetados pelo cenário pandêmico. 
Aliado a isso, os Centros de Referência de Assistência Social (CRAS) locais podem contribuir, dando suporte na inscrição dos seus usuários para o recebimento do auxílio.

Não se pode esquecer da população carcerária que é seriamente vulnerável à contaminação do novo coronavírus, tornando imprescindível a implementação de medidas emergenciais para enfrentar a pandemia junto a este grupo social. Liberação de presos maiores de 60 anos, que já cumpriram suas penas, que estejam em regime semiaberto, presas gestantes, assim como aquelas que estejam com as suas crianças e detentos com condições médicas preexistentes - acometidas por hipertensão, doenças cardíacas, diabetes, pessoas que vivem com HIV/Aids, dentre outras enfermidades suscetíveis de agravamento a partir do contágio pelo Covid-19, ou que se enquadrem em situação de risco de saúde agravado, passando-lhes para regime de prisão domiciliar humanitária (Pires, 2020).

\section{Considerações Finais}

É nesta realidade, sob esta forma capitalista de produção e reprodução do ser humano, que nos deparamos com uma pandemia que ameaça a vida: o Coronavírus. Apesar da ideia de que o vírus iguala a todos diante do contágio e da morte, sabemos que não é verdade. A população mais pobre está mais disposta à contaminação e transmissibilidade da doença, sem falar da falta de acesso aos equipamentos de proteção e às terapias necessárias ao tratamento.

É importante frisar que atualmente é sensato refletir sobre o fato de que os ecossistemas sustentam as economias (e a saúde); economias não sustentam os ecossistemas. O Covid-19 nos lembra que o tratamento desrespeitoso com a natureza, incluindo a biodiversidade de plantas e animais, tem consequências e, quando são prejudicadas, em última instancia, os seres humanos também são.

Os oprimidos de hoje são os pobres, as maiores vítimas deste sistema que acorrenta, explora e leva à morte. Esta diferença de classe é gritante no Brasil e atualmente a desigualdade social é uma das maiores do mundo. Há uma imensa massa de desempregados e miseráveis vendendo sua força de trabalho por um salário de fome, enquanto poucos, detentores dos meios de produção e do capital, acumulam riquezas e influenciam, segundo os interesses econômicos, não só os poderes da república, mas uma grande massa disposta, pela cegueira, a viver segundo os interesses deste poder.

Qualquer quarentena é sempre discriminatória, mais difícil para uns grupos sociais do que para outros e impossível para um vasto grupo de cuidadores, cuja missão é tornar possível a quarentena ao conjunto da população.

A pandemia e a quarentena estão a revelar que são possíveis alternativas, que as sociedades se adaptam a novos modos de viver quando tal é necessário e sentido como correspondendo ao bem comum. Esta situação torna-se propícia a que se pense em alternativas ao modo de viver, de produzir, de consumir e de conviver nestes primeiros anos do século XXI. Na ausência de tais alternativas, não será possível evitar a irrupção de novas pandemias, as quais, aliás, como tudo leva a crer, podem ser ainda mais letais do que a atual.

Enfim, só com uma nova articulação entre os processos políticos e os processos civilizatórios será possível começar a pensar numa sociedade em que humanidade assuma uma posição mais humilde no planeta que habita. De outro modo, se a vida humana continuar a pôr em causa e a destruir todas as outras vidas de que é feito o planeta Terra, é de esperar que essas outras vidas se defendam da agressão causada pela vida humana e o façam por formas cada vez mais letais. Nesse caso, o futuro desta quarentena será um curto intervalo antes das quarentenas futuras.

\section{Referências}

Altieri, M. A., Nicholls, C. I. (2020). A Agroecologia nos tempos do Covid-19, 2020. Disponível em: https://www.clacso.org/a-agroecologia-nos-tempos-docovid-19/.

Bmj Best Practice. (2020). Doença do coronavírus 2019 (Covid-19). Disponível em: https://bestpractice.bmj.com/info/pt/. 
Research, Society and Development, v. 11, n. 3, e41111322685, 2021 (CC BY 4.0) | ISSN 2525-3409 | DOI: http://dx.doi.org/10.33448/rsd-v11i3.22685

Castro, D., Seno, D. D., Pochmann, M. (2020). Capitalismo e a Covid-19. São Paulo.

Chen, Y, Guo, Y, Pan, Y. et al. (2020). Análise estrutural da ligação ao receptor de 2019-nCoV. Biochem Biophys Res Commun. 17 de fevereiro. Pii: S0006291X (20) 30339-9.

Dias, D. de S., Silva, M. F. (2010). Como escrever uma monografia: manual de elaboração com exemplos e exercícios. São Paulo: Atlas.

Fontes, G. (2020). Quatro efeitos negativos da Covid-19 na economia brasileira, e dois que servem de consolo. 2020. Disponível em: https://www.gazetadopovo.com.br/economia/efeitos-covid-19-coronavirus-economia-brasileira-ifi/

Gil, A. C. (2008). Métodos e técnicas de pesquisa social. 6. ed. Ediitora Atlas SA.

Grupo de Estudo Coronaviridae do Comitê Internacional de Taxonomia de Vírus. (2020). As espécies coronavírus relacionado à síndrome respiratória aguda grave: classificação de 2019-nCoV e denominação SARSCoV-2. Nat Microbiol. Abril 2020; 5 (4): 536-44.

Hanff, TC; Harhay, MO; Brown, TS et al. (2020). Existe associação entre a mortalidade pelo Covid-19 e a sistema renina-angiotensina: um chamado para investigações epidemiológicas. Clin Infect Dis.

Li, Q., Guan, X., Wu, P. et al. (2020). Dinâmica de transmissão precoce em Wuhan, China, de novos infectados por coronavírus pneumonia. N Engl J Med. 202026 de março; 382 (13): 1199-207.

Lu, R., Zhao, X, Li, J. et al. (2019). Caracterização genômica e epidemiologia do novo coronavírus de 2019: implicações para origens de vírus e ligação a receptores. Lanceta. 22 de fevereiro de 2020; 395 (10224): 565-74.

Organização Mundial de Saúde - OMS. (2020). Novo coronavírus: China. https://www.who.int/csr/don/12-january-2020-novel-coronavirus-china/en/.

Pires, M.. As políticas que estão sendo adotadas para o combate ao Covid-19: Experiência internacional e o Brasil. 2020. Disponível em:https://observatoriopolitica-fiscal.ibre.fgv.br/posts/politicas-que-estao-sendo-adotadas-para-o-combate-ao-covid-19-experiencia-internacional-e-o.

Ren, LL., Wang, YM., Wu, ZQ. et al. (2020). Identificação de um novo coronavírus causando pneumonia grave em humano: um estudo descritivo. Chin Med $\mathrm{J}$ (Engl).

Salto, F. S., Pellegrini, J. A., Couri, D. V. (2020). IFI-Relatório de Acompanhamento Fiscal. N. 38.

Zou, X., Chen, K., Zou, J., et al. (2020). Análise de dados de RNA-seq de célula única na expressão do receptor ACE2 revela o risco potencial de diferentes órgãos humanos vulneráveis à infecção por 2019-nCoV. Front Med. 